\title{
Papers
}

\section{Integrating the value of salespeople and systems: Adapting the benefits dependency network}

Received (in revised form): 21st September, 2008

\section{Beth Rogers}

is Principal Lecturer in Sales Management at University of Portsmouth Business School.

\section{Merlin Stone}

is Research Director at WCL and Visiting Professor of Marketing at University of Portsmouth Business School.

\section{Bryan Foss}

is a Non-Executive Director, Board Advisor and Managing Director of Foss Initiatives.

Keywords customer relationship management, sales force automation, sales productivity, return on investment, project management, sales management

Abstract Business-to-business (B2B) companies invest in customer relationship management (CRM), integrated with sales force automation (SFA) to achieve a return on investment, through improved sales force productivity, sales revenue, costs, customer satisfaction, process accuracy and customer knowledge. However, the devil is in the detail. CRM and SFA are multi-faceted. There are two main obstacles to successful implementation. One is the need for the customer to get some benefit out of the system; the other is ensuring that employees who are expected to use the system actually buy-in to its benefits, including what benefit they will gain as individuals. However, much planning is needed to manage the risks involved. The 'benefits dependency network' (BDN), ${ }^{1}$ designed to develop routes to successful implementation of IT, has been tested in CRM projects. The factors for success in CRM implementation in B2B companies, where the sales force must be involved, are many and varied, including proactive sales management, creating champions, consultation, training, incentives and culture change. Practicalities such as incremental application of the technology and a wide portfolio of metrics to monitor progress are also critical. In the light of the special considerations of sales force involvement, the authors propose an adaptation of the BDN to suggest a generic map for the implementation of CRM (with SFA) in B2B markets. This paper is based on the authors' secondary research for two commercial sponsors in the utilities sector, supplemented by the authors' extensive experience of working in this area. Journal of Database Marketing \& Customer Strategy Management (2008) 15, 221-232. doi:10.1057/dbm.2008.19

Beth Rogers

Portsmouth Business School Richmond Building

Portland Street Portsmouth P01 3DE

Tel: 02392844017 ;

Fax: 02392844037

\section{INTRODUCTION}

Customer relationship management (CRM) systems have been around since the mid- 1990s, when they fairly quickly became associated with problems. Rigby et al. ${ }^{2}$ noted a number of contemporary analyst 
reports quoting high levels of failure, escalating implementation costs, and dissatisfaction from managers, customers and users. Wilson et al. ${ }^{3}$ noted that failure rates were still 'obstinately high' (p. 771). The technology has been around for some time and the consultants that work for the software houses have a great deal of relevant skills and experience. ${ }^{4}$ So the cause of failure usually lies deeper. The history of company systems has been a focus on product, operations and the movement of money. The intricacies of customer knowledge and how to leverage it have been left to the salesperson's intuition. Changing all that without damaging knock-on effects is a significant challenge.

To many, CRM is the strategy and process supporting a 'relationship vision' for a company, ${ }^{5}$ but most commentators focus on practicalities. Ling and Yen ${ }^{6}$ observe that CRM is a process for using information about customers. They conclude that the primary purpose of that is to improve sales productivity and efficiency. The bottom-line focus is also strong in the literature; for example, Bull ${ }^{7}$ argues that CRM must make a contribution to profitability by making customer relationships more efficient and effective. Managers may choose their own definition for CRM (and SFA), but they cannot act in isolation. Employees and customers may have their own ideas about what they expect from it.

In an in-depth study of ten B2B supplier-customer dyads, Richard et al. ${ }^{8}$ found that customers are most interested in suppliers using CRM to manage knowledge, that is, help them to understand their business and communicate better in a customer-oriented way. It has been suggested that customer knowledge management $t^{8,9}$ and customer experience management ${ }^{10}$ are critical additions to CRM. Suppliers may be able to take this on board, but leverage of customer knowledge is unlikely to happen for the customer without the active engagement of salespeople. This is particularly clear when it comes to linking CRM with sales force automation (SFA) in order to merge the benefits of better information (from the CRM system) with the salesperson's relationship development activity at the customer interface. The very expression 'sales force automation' must rankle with a profession associated with individualism and intuition, and still motivated to a large extent by individual rewards.

However, when the authors reviewed the benefits expected from CRM/SFA and reported for them, sales force focus was lacking. The purpose of this discussion is to design a model that has a specific step to ensure that benefits for them are designed into the implementation plan. However, note that CRM systems and SFA have some separate and some overlapping functions. They will be referred to separately when particular studies have focused on one or the other. In practice they are usually integrated. In this paper the acronym CRM/SFA will be used to indicate an integrated system.

\section{THE BUSINESS RATIONALE FOR CRM/SFA}

In accordance with many of the claims of the software vendors, CRM/SFA does have a business case, although care has to be taken of the time it takes to achieve full returns. It can take up to seven years to realise benefits from full-scale systems. ${ }^{11}$ A focus on small incremental steps seems to keep up the pace of returns. ${ }^{12,13}$ Software vendor SAP claims returns between 15 and 144 per cent from 24 (predominantly B2B) customer case studies, with strategic focus on productivity, lower costs and improving revenue generation. ${ }^{14}$ The robustness of the business case will be affected by what gets included as costs. The cost of the software is not the only factor. Successful implementations are marked by significant sums on non-IT elements, including 
consultation and training, incentives and project management. ${ }^{12,4,15,16,13}$

Contingencies are usually allowed for, but scenario planning to identify possible hidden costs (such as an increase in customer enquiries when they first experience the new system, turnover of sales staff unwilling to adopt the new system) is also prudent.

The successful results of salespeople's use of CRM/SFA technology that improve return on investment include the following.

\section{Improved sales revenue}

Given the importance of organic growth ${ }^{17}$ in recent years, it is not surprising that up-selling and cross-selling are frequently expected. Engle and Barnes' ${ }^{11}$ cross-cultural study of the payback for SFA alone concluded that 16.4 per cent of the sales growth observed in the participating companies could be attributed to its use. Sales and marketing professionals have historically associated their success with revenue growth. (Of course, that has to be profitable growth.) Without the benefit of revenue growth in the forefront, the whole package of benefits might have less resonance to them.

\section{Better sales productivity}

SFA is assumed to make salespeople more efficient, both in how they allocate time to customers and in how they use that time. Moutot and Bascoul ${ }^{18}$ found that with SFA, the proportion of successful sales calls increased significantly, which was attributed to call planning functions that filtered out potentially ineffective calls. A sales portal for field and telesales representatives in IBM provided 2 hours per week per person productivity gain. Those using the tool saw a 45 per cent improvement in revenue per opportunity over the control group. ${ }^{19}$ Best performance is achieved when bringing transaction and non-transaction data together. ${ }^{20}$

\section{Better customer satisfaction, leading to retention}

The focus for return on investment tends to be on internal benefits, but without benefits for the customer, those internal benefits could be wiped out. In a metaanalysis of academic research papers on the topic of CRM and sales, Landry et al. ${ }^{21}$ concluded that IT investment does enhance the exchange relationship with customers, provided that salespeople can switch to more value-adding activity. Thus, the 'Inside IBM' customer portal generated $\$ 2.2$ billion of business during the pilot with 58 customers. It was a single interface designed to address customer pain points. Flexible and personalised, it gave customers some control over interactions. It was considered to have an intuitive and user-friendly design. Customers found that they had easy access to IBM's knowledge base and decision processes, including bills, contracts and orders. ${ }^{22}$ Self-service for routine tasks means that sales calls can focus on more strategic matters.

\section{Better process accuracy}

Regular lower costs tend to follow from better processes, but process efficiency also reduces incident-based hidden costs of rework and complaints, and has a value in its own right — improving the quality of working life for process users (salespeople and customers) and the accuracy of data for decision-makers (eg sales managers). Process excellence is a critical element of CRM. ${ }^{5}$

\section{Customer knowledge/understanding} Richard et al. ${ }^{8}$ found B2B customers to be very interested in suppliers using CRM to manage knowledge, that is, help them understand their business and communicate in more customer-oriented ways. Customer analytics is still an under-exploited aspect of CRM. Combining descriptive information on customer characteristics (eg from an external source such as Dun and Bradstreet) and events (from a news feed provider) with 
transaction histories and any behavioural/ attitudinal data provides the potential for predictive prompts to salespeople. ${ }^{20}$ Thus, a fall in orders may indicate risk of customer defection. A customer analytics system can then analyse the customer's lifetime value information and past behaviour (such as complaining about poor service) and suggest a response, such as contacting, diagnosing the situation and making a relevant offer.

\section{Lower costs}

Industry analysts Gartner report that CRM systems have helped companies to reduce sales, service and operational costs. ${ }^{23}$ Most implementers of CRM are looking for cost savings, which are associated with other elements described here, such as improved productivity and better processes. For example, McKim and Hughes ${ }^{24}$ identify cost savings arising from better targeting of customers.

\section{Enhanced reputation}

Although rarely a directly planned benefit, use of CRM/SFA that impresses customers can be associated with improving a company's reputation. ${ }^{9}$

\section{Better resource allocation}

There is surprisingly little exploration of the value of CRM/SFA systems' contribution to better management decision-making, although any system generating managing data and generating analytics should be used for resource allocation. Better sales pipeline accuracy and visibility throughout the company must include better resource allocation. In a discussion of IBM's implementation of salesperson portals, Lawrence et al. ${ }^{19}$ explain that sales managers were equipped with linked web-based tools enabling them to steer sales resource to the best opportunities. The active group achieved 5 per cent better results than the control group. This was on top of the productivity gains attributed to salespeople. Although it may not have much glamour as a 'lead' objective, the contribution of the CRM/SFA system to better sales management should be tracked and evaluated.

\section{EXTENDING SOURCES}

From a commercial research sponsor's point of view, the robustness of academic studies is attractive, but needs to be supplemented with up-to-date exemplars. Although case study research has been conducted, there was not enough that was specifically business-to-business (B2B) or Europeanfocused. In addition to the findings from the literature described above, the research team identified 20 detailed case studies of CRM success in named B2B companies, available on software vendors' websites.

As the customer was quoted, it was considered reasonable to use these examples to explore the advantages claimed. Having supplemented the literature with this checking procedure, the research team proceeded to link the results that companies plan to achieve from CRM/SFA (see Figure 1) as a preliminary step to modelling the delivery of benefits.

\section{IMPLEMENTATION CHALLENGES}

Many companies have achieved desirable outcomes and benefits from implementing CRM and SFA systems, but research also documents extensive problems with implementing it. Before modelling how benefits can be delivered, it is worthwhile visiting the critical barriers to implementation.

\section{Not enough to impress the customer}

The customer experience is not necessarily enhanced by $\mathrm{CRM}^{23} \mathrm{~B} 2 \mathrm{C}$ and $\mathrm{B} 2 \mathrm{~B}$ customers have criticised CRM technology for focusing too much on standardised practices, such as data entry and improving business practices, instead of the relationship. The customers perceive relationships as dependent on people, not systems or 


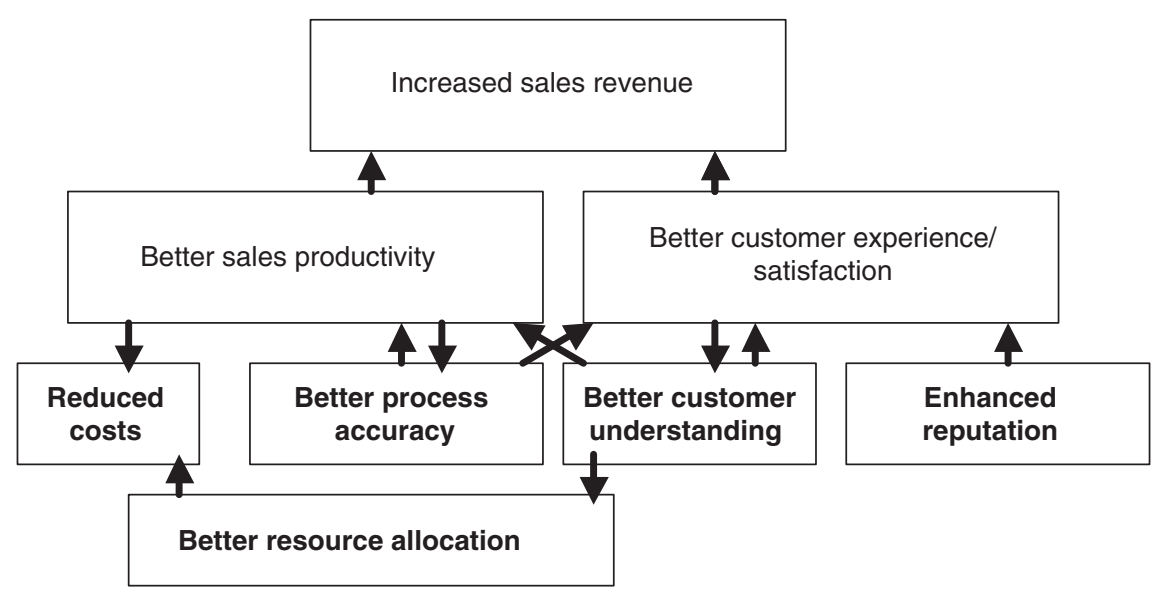

Figure 1: List of characteristic results of successful CRM/SFA implementation and possible linkages

computers. There is a danger of separating the relationship with the customer from day-to-day activities with the online service appearing remote and unresponsive to the needs of the customer's business. ${ }^{25}$ On the other hand, the purchasing profession is extremely interested in achieving cost savings for commoditised products via e-channels to suppliers, or even e-auctions. B2B customers want time savings and efficiency, ${ }^{26}$ although technology-based service delivery systems must work well, or the customer will be dissatisfied. Because e-channels are always an option, visits from sales representatives need to focus on value-adding opportunities. ${ }^{27}$ In an era of increasing customer power and reduced brand differentiation through product or service characteristics, the customer experience can be critical to company success. CRM/SFA can impress the customer if it helps to turn customer data into relevant business knowledge. 8,9

\section{User resistance}

Landry et al. ${ }^{21}$ pinpointed a vivid insecurity in salespeople when faced with CRM/SFA systems - the fear of losing their jobs. This can be inferred from the very term 'sales force automation'. Being involved in designing the system may reassure them to some degree that the company has a longterm vision of them using it, but even if they perceive that the system is about sales force productivity rather than sales force reduction, there may still be resistance. The technology acceptance model (TAM) ${ }^{28}$ suggests that usage behaviour is determined by two related beliefs: perceived ease of use and perceived usefulness. SFA implementation rarely runs smoothly. People have different attitudes and beliefs about the use of technology. When Robinson et al. ${ }^{15}$ applied the TAM to salespeople, they found that they are not very different from norms in other professions - people who have a favourable attitude towards technology in the first place are most likely to intend to use the technology offered. In a B2B environment, it might be assumed that acceptance of technology could be assumed, but the literature suggests that any user needs convincing.

If salespeople believe that technology will help them to 'work smarter' (eg speedy access to call relevant information, better targeting so that more calls result in a sale), they will use it. Perceived usefulness seems to fade when it comes to the administrative tasks. SFA's reporting functions have a negative effect on salesperson behaviour. ${ }^{18}$ 


\section{USING A MODEL TO PLAN IMPLEMENTATION}

To achieve the right outcomes, benefits and business objectives from CRM/SFA, while taking into account the possible barriers to implementation and overcoming them, requires a robust project plan. In the 1990s, Professor John Ward and his team at the Information Systems Research Centre at Cranfield School of Management created a process to identify the benefits from the use of information systems, but found that client companies were using it for many types of change management. ${ }^{29}$ The benefits management model has been successfully tested in a number of B2B companies to track cause and effect. 'There are no direct benefits from IT, IT only enables or creates a capability to derive benefits .... Things only get better when people start doing things differently'. ${ }^{30}$

The principle of the benefits dependency network $(\mathrm{BDN})$ is that between the IT input and the desired business objectives are several necessary change management steps. IS/IT functionality enables a business change that delivers a business outcome that achieves benefits and so the original intent of the content is satisfied. ${ }^{1}$ The authors emphasised the difference between an outcome and a benefit. Because of the application of new function via a CRM system (eg customers re-ordering standard products through a portal), a company might be able to decide on an outcome, such as reducing the size of the sales force, which delivers the benefit of reduced costs. Alternatively, it might maintain its size so salespeople can spend more time adding value to customers (outcome), which should improve sales and/or customer satisfaction (benefit). Managers have to make decisions in order to achieve benefits, which are not automatically delivered by content (see Figure 2). So, in planning an IT system, project management tools should be supplemented by a map linking IT functionality through enabling changes,

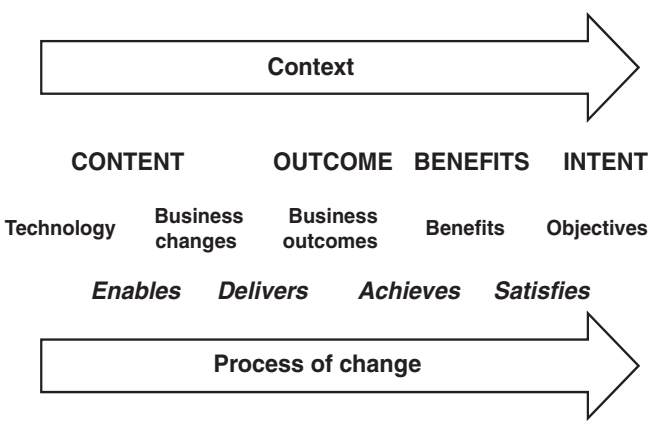

Figure 2: The road to benefits Adapted from Ward and Elvin (1999)

business changes and business benefits to investment objectives. Some of these in themselves may have more than one layer of cause and effect.

Given the inhibitors to success with CRM + SFA, this model has a lot to offer in terms of the thought processes needed to design a project plan to drive the necessary changes. First of all, we can distinguish between investment objectives and business benefits. From a stockholder's point of view, the investment objective (from diagram 1) is likely to be increasing (profitable) sales revenue. The rest of the items need careful consideration. Which is the chicken and which is the egg? Better process accuracy, better customer understanding, better resource allocation and enhanced reputation are most likely to be categorised as outcomes in the BDN, and the inter-relationship between them will need to be captured. 'Reduced costs' is combined into the benefit of better sales productivity. Customer satisfaction is the other benefit contributing to the achievement of the investment objective. Some of the outcomes can contribute to both benefits.

Wilson et al. ${ }^{3}$ applied the BDN in case studies of CRM implementation. Instead of tracking resources over time in a standard way, a chain of cause and effect was mapped. The authors found that this led to rigour in the thinking associated with the implementation, avoidance of technology 
rather than business objectives leading the project and identification of companyspecific needs in the plan. They summarised the benefits of the BDN as economic (such as the alignment of technology with business objectives) and political (such as providing a framework for communicating the case for change), ensuring the necessary changes are identified and enabling better control through appropriate metrics.

The BDN, however, was designed with an internal focus - a company's need to manage its return on an IT investment. It is worthwhile considering another angle the customer view. The authors noted an overlap between the principles of the BDN and Shaw's 'five perspectives methodology' of marketing effectiveness. ${ }^{31}$ Shaw argued that in order to track the value of marketing 'inputs' intended to improve company performance, the effect of inputs on changing customer motivation must be mapped, followed by the link between changed motivation and changes in customer behaviour, and then tracking the link between behaviour changes and outcome for the supplier, for example, increased revenue. Shaw warned of the potential confusion between motivation measures, such as satisfaction, and behaviour measures, such as repeat purchases.

Given that one of the major barriers to success with CRM and SFA is insufficient benefit for customers, the authors were keen to accommodate this customerfocused view designed for marketing investments into a BDN framework, creating different headings to provoke this thinking (see Figure 3). The idea of separately monitoring motivation and its link to behaviour is also relevant to employees' role in change, which suggested that an additional step in the BDN might help to establish that imperative.

Having disentangled outcomes from benefits and objectives, attention was also required at the content/input end of the model. First of all, it was necessary to step

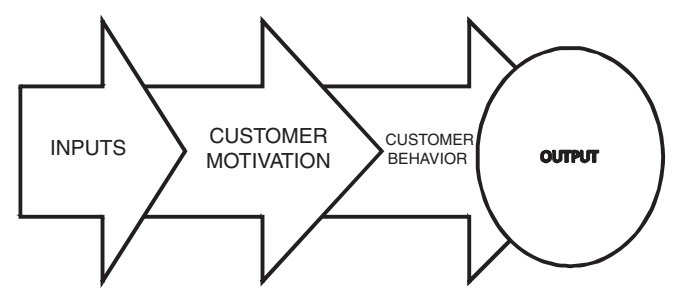

Figure 3: Inputs and outputs in marketing investments

Adapted from Shaw (1998)

back and check documentary sources explaining the business changes necessary to ensure successful CRM/SFA implementation.

\section{SUCCESSFUL IMPLEMENTATION}

What then, are the factors of success in implementing CRM/SFA? Extant literature offers a variety of factors that could be considered 'business change' content for the BDN model. The common theme throughout is the proactive facilitation of changes in technology users' behaviour.

\section{Senior management sponsorship}

Many articles refer to the need for leadership from the top to drive the business changes necessary for the successful implementation of CRM/SFA. ${ }^{32,2,7}$ SAP reports that 22 of their 24 best-practice CRM case studies implemented significant change management programmes alongside CRM implementation. ${ }^{14}$

In a study of MRPII systems, Brown ${ }^{33}$ noted that senior management underestimated, undervalued and even ignored the process of change management necessary to implement the systems properly. Foss et al. ${ }^{13}$ also observed the problem of lack of senior management engagement in CRM, and suggest that executives may be unaware of the high risks associated with an unsatisfactory outcome. Troubled CRM implementations can have serious financial consequences for the company and their careers, particularly as there are corporate governance issue at 
stake such as traceability of actions and the handling of customer information. Pries and Stone ${ }^{34}$ reported the CRM consultants' view that senior managers usually failed to get involved and expected CRM to just happen.

Senior managers have a number of tasks to establish leadership, which include setting the right structure, explaining and reinforcing the case for change, choosing the right metrics and establishing the right rewards. The right organisational structure ensures momentum for CRM implementations. Foss et al. ${ }^{13}$ note that successfully managed implementations usually have a Change Board ensuring proper planning and involvement of stakeholders, a CRM Board including an IT Advisory Board and an Audit team tracking achievement, as well as Programme Streams for the building blocks of the system. Regular meetings are necessary to maintain momentum, and programme assurance at key checkpoints, which may involve an external expert who can flush out buried problems.

With the right organisation in place, communication channels will be clear. Communicating the benefits of the system to employees was a common factor in SAP's success stories. ${ }^{14}$ Professionals prefer to be asked rather than told, particularly where the new order seems threatening. Successful companies seem to have rolled out consultations with small groups of ten, explaining the overall vision and plans for the system and then discussing how the system might affect them. ${ }^{4}$ Users of CRM/ SFA also need to know what success with the new system will look like. As with any investment, just measuring inputs and outputs is not particularly helpful. Ways have to be found to measure qualitative factors. Shaw's ${ }^{31}$ model of linking inputs to changes in customer motivation and on to changes in customer behaviour and then output provides a basis for tracking cause and effect. Successful implementation is likely to be associated with performance pay for operational managers, but senior managers also need to consider how they reward successful use of the new systems. Robinson et al. ${ }^{15}$ and Yim et al..$^{35}$ have commented on the need to reward superior CRM performance at all levels.

\section{Sales management}

Senior managers will obviously delegate day-to-day matters to operational managers. It is sales managers who can guide re-engineering of sales processes, build teams, involve salespeople in development and use the analytics to improve decisionmaking. ${ }^{16}$ Honeycutt ${ }^{36}$ noted, from a special collection of empirical studies of SFA, that the sales manager plays a significant role in its success. He/she needs to plan and communicate well, recruit with technology capability in mind, provide training, set expectations correctly and be aware of legal aspects of using technology.

Sales managers can also identify and leverage systems champions. In 2000, Ventakesh and Davis ${ }^{37}$ proposed an extended TAM model, and focused on the influencing factors in 'perceived usefulness'. They recommended the use of social influence to positively affect perceived usefulness. People will identify prestige with use of a system that is used by credible and admirable colleagues. Jones et al., ${ }^{38}$ Corner and Rogers ${ }^{4}$ and Ahearne et al. ${ }^{39}$ have also noted that salespeople are influenced by their colleagues and this will impact his/her perceptions concerning both the usefulness and the ease-of-use of the system.

Another critical role for sales managers is specifying appropriate training and making sure that salespeople get enough of it and get value out of it. Extensive training is advocated by many researchers. $6,35,15,32$ Salespeople are often reluctant volunteers for training, but Ekinci et al. ${ }^{40}$ found that only 50 per cent of the users felt competent enough with CRM systems, and 30 per cent wanted more training than they got. 
Last but not least, sales managers will be in the forefront of any problems and conflict caused by the implementation of new systems, and will need to resolve them. Conflicts are very common in the workplace and may arise from things that are easy to fix, such as lack of communication or stress caused by competition for scarce support. Playing the shame game is one approach that has been tried with the problem of lack of contribution of information. Salespeople feel that they get poor output and admit to poor input. A preliminary exercise to a re-launch might be to raise awareness of the impact of poor input on other people's jobs. Managers at a US company gathered data about the poor quality of order information that salespeople left for colleagues to follow up: 700 per month were incomplete. Each was given their own statistics, so that it was obvious to them that they were part of the problem. The following month, incomplete order messages were down to $259 .{ }^{41}$

\section{Project management}

Other factors for success lie with technology-proficient project managers. They certainly need to apply the full spectrum of their skills to the pre-requisites, co-requisites and post-requisites inherent in the project plan, and to manage the unique risks associated with customer-facing systems.

It is hard to value improvements in customer relationships. ${ }^{42}$ Trials or pilots followed by review and consolidation can simulate the effect of CRM/SFA systems versus a 'control' situation of no CRM/ SFA. This helps to build confidence in the potential benefits of the system and flushes out problems early on. Foss et al. ${ }^{13}$ suggest a 'pay-as-you-go' approach to CRM implementation — starting small and reinvesting the return so that early gains drive the expansion of the system. Clear objectives and their translation into beneficial outcomes is at the core of good CRM governance. Tracking of cause and effect is good practice. Companies that develop a causal model achieve about 5 per cent better return on equity. ${ }^{43}$

There are many risks associated with a CRM/SFA implementation. Poor implementation will harm the customer view of the firm and damage its reputation. The application of CRM technologies has, in the past, been associated with the risk of making the customer experience worse. ${ }^{2}$ It is vitally necessary to check that the customer experience is central to CRM/ SFA design. ${ }^{23}$ Operational problems are possible and will cause loss of business. The company's internal social system is also at risk. Spier and Venkatesh ${ }^{44}$ suggest that SFA technology causes power redistribution between managers and salespeople. The idea that SFA leads to increased monitoring often leads to resentment. Issues such as these have to be frankly explored in culture change events such as consultations.

Information is at risk for supplier and customer, so security is key to design. ${ }^{45}$ Because CRM projects have been noted for escalating costs, financial risk also has to be managed. Many companies now adopt fixed price contracts when employing vendors and service providers. Within that, good change management procedures are essential in order to maintain an equitable financial relationship with contractors. Senior managers should make sure the budget is flexible and accommodates postimplementation reviews.

\section{EXTENDING THE BDN}

The requirements of a concept model are that it should be easily understood, encompass relevant factors and their relationships and organise thinking, but without unnecessarily constraining different kinds of approaches. ${ }^{46}$ The BDN already has a track record of achievement, and it is proposed that this can be built on by 


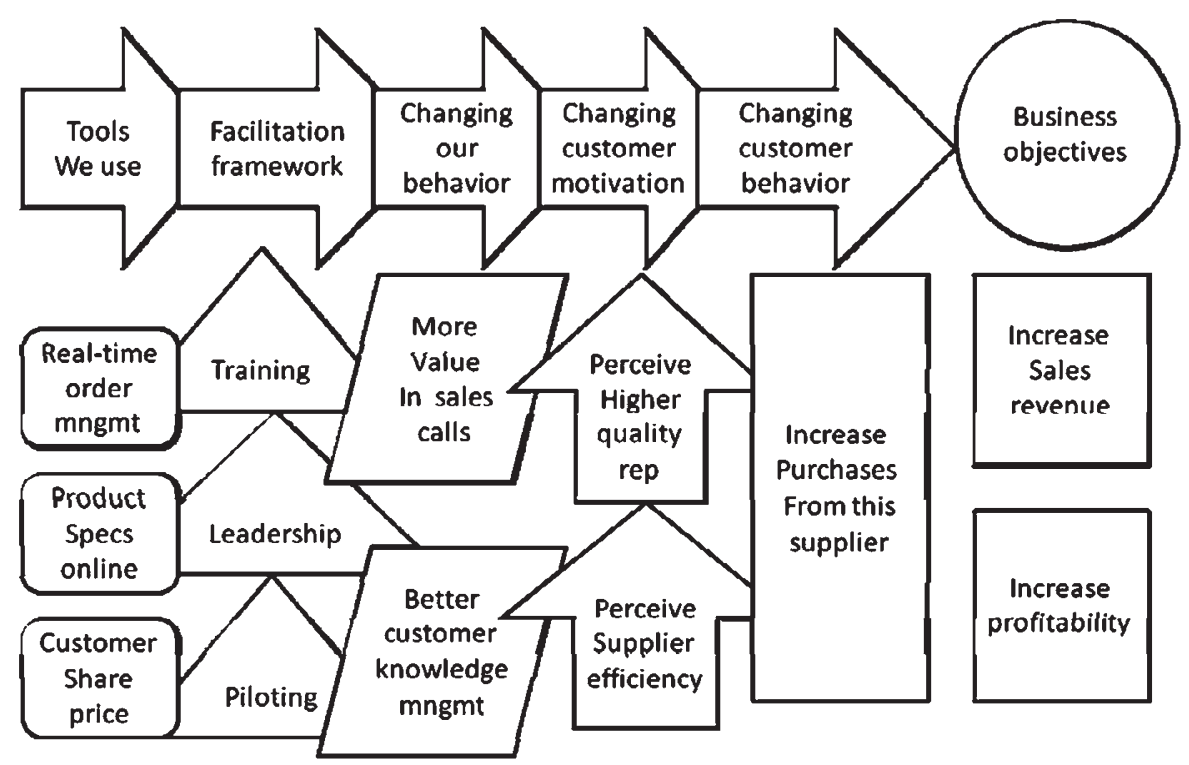

Figure 4: Benefits dependency in CRM/SFA

adapting the customer-centric measurement approach of Shaw ${ }^{31}$ and adding a

'facilitation framework' step to accommodate the need for focus on employee buy-in.

In the past, companies may have installed IT tools and measure whether or not a business objective is achieved as a result, for example, install real-time order management and we will get more sales. Taking into account John Ward's well-proven benefits dependency model and Bob Shaw's model of marketing measurement, companies could track the progress of CRM/SFA by measuring progress towards business objectives through project plans and metrics encompassing the application of the tool, the facilitation framework that leads on to salespeople using the tool effectively, changes in customer motivation as a result and changes in customer behaviour leading to improved sales productivity (see Figure 4).

Before a supplier can get into changing its input to customers as a result of implementing new IT tools, it is necessary to gain user commitment to the tools so that the input can be achieved. And then, the customer has to notice how the tools are changing the supplier's 'input' to them. Perhaps the new system means that the salesperson gives them better and speedy information. If this affects the customer's motivation, for example, they perceive that the supplier is more efficient, then they may change their behaviour, for example, by giving that supplier a 'preferred' status so that more orders will be placed leading to the supplier increasing its revenue.

This is a small and scaled-down example of a full project map. Companies may wish to focus the detail of their network models on other business objectives than those shown in this example. The critical point is that, given research to date on the implementation of CRM/SFA in B2B companies, extensive mapping of cause and effect using all six steps appears to be necessary to manage the change successfully.

\section{CONCLUSION}

Successful implementation of CRM/SFA is not about great technology or great project management, although both are helpful. In order to deliver shareholder value, the system must deliver some benefits to 
customers that affect their buying behaviour, and before that can be achieved; employees must be enthusiastic adopters of the system and its benefits to them. Sales staff have to learn how to operate differently, and make use of technology to deliver better value to customers, alongside accepting that some customers may prefer technology-only channels for some interactions. Success appears to require both 'soft' (eg consultation) and 'hard' (eg incentives) management techniques. The mapping and planning of progress from any given start (or re-start) point to achieving business objectives is complex and requires significant discussion and thought. The sixlink adaptation of the benefits dependency model specifically for CRM/SFA suggested here is based on a knowledge of best practice to date. A second phase of research is planned with additional business sponsors to test its value.

\section{References}

1 Ward, J. and Elvin, R. (1999) 'A new framework for managing IT-enabled business changes', Information Systems Journal, Vol. 9, No. 3, pp. 197-221.

2 Rigby, D. K., Reichheld, F. F. and Shefter, P. (2002) 'Avoid the four perils of CRM', Harvard Business Review, Vol. 80, No. 2, pp. 101-109.

3 Wilson, H., Clarke, M. and Smith, B. (2007) 'Justifying CRM projects in a business-to-business context: The potential of the benefits dependency network', Industrial Marketing Management, Vol. 36, No. 6, pp. 770-783.

4 Corner, I. and Rogers, B. (2005) 'Monitoring qualitative aspects of CRM implementation: The essential dimension of management responsibility for employee involvement and acceptance', Journal of Targeting, Measurement and Analysis for Marketing, Vol. 13, No. 3, pp. 267-274.

5 Gordon, I. (2002) 'Best practices: Customer relationship management', Ivey Business Journal, Vol. 67, No. 2, pp. 67-72.

6 Ling, R. and Yen, D. C. (2001) 'Customer relationship management: An analysis framework and implementation strategies', Journal of Computer Information Systems, Vol. 41, No. 3, pp. 82-98.

7 Bull, C. (2003) 'Strategic issues in customer relationship management (CRM) implementation', Business Process Management Journal, Vol. 9, No. 5, pp. 592-602.

8 Richard, J. E., Thirkell, P. C. and Huff, S. L. (2007) 'An examination of customer relationship management (CRM) technology adoption and its impact on business-to-business customer relationships', Total Quality Management and Excellence, Vol. 18, No. 8, pp. 927-945.

9 Gibbert, M., Leibold, M. and Probst, G. (2002) 'Five styles of customer knowledge management and how smart companies use them to create value', European Management Journal, Vol. 20, No. 5, pp. 459-469.

10 Kiska, J. (2002) 'Customer experience management', CMA Management, Vol. 76, No. 7, pp. 28-30.

11 Engle, R. L. and Barnes, M. L. (2000) 'Sales force automation usage, effectiveness and cost-benefit in Germany, England and the United States', Journal of Business and Industrial Marketing, Vol. 15, No. 4, pp. 216-241.

12 Rogers, B. and Ryals, L. (2003) 'Managing "Wicked" CRM projects - The role of marketers in best practice implementation', Customer Management, Vol. 11, No. 3, pp. 34-37.

13 Foss, B., Stone, M. and Ekinci, Y. (2008) 'What makes for CRM system success - Or failure?' Database Marketing and Customer Strategy Management, Vol. 15, No. 2, pp. 68-78.

14 Anon. (2006) 'mySAP CRM delivers actionable ROI insight', in mySAP CRM ROI Review 2006, conducted by Peppers and Rogers for SAP (Walldorf). Retrieved 24th May, 2008 from the SAP Global website: www.sap.com/solutions/ business-suite/crm/pdf/ROI_Intelligence_Report_ 2006_Updated.pdf.

15 Robinson, L., Marshall, G. and Stamps, M. (2005) 'Sales force use of technology: Antecedents to technology acceptance', Journal of Business Research, Vol. 58, No. 12, pp. 1623-1631.

16 Raman, P., Wittmann, C. M. and Rauseo, N. A. (2006) 'Leveraging CRM for sales: The role of organizational capabilities in successful CRM implementation', Journal of Personal Selling and Sales Management, Vol. 26, No. 1, pp. 39-53.

17 Hess, E. D. and Kazanjian, R. K. (2006) 'The search for organic growth', Cambridge University Press, Cambridge.

18 Moutot, J. -M. and Bascoul, G. (2008) 'Effects of sales force automation use on sales force activities and customer relationship management processes', Journal of Personal Selling and Sales Management, Vol. 28, No. 2, pp. 167-184.

19 Lawrence, R., Perlich, C., Rosset, S., Arroyo, J., Callahan, M., Collins, J. M., Ershov, A., Feinzig, S., Khabibrakhmanov, I., Mahatma, S., Niemaszyk, M. and Weiss, S. M. (2007) 'Analytics-driven solutions for customer targeting and sales force allocation', IBM Systems Journal, Vol. 46, No. 4, pp. 797-816.

20 Stone, M., Foss, B., Henderson, I., Irwin, D., O'Donnell, J. and Woodcock, N. (2003) 'The quality of customer information management in customer life cycle management', Journal of Database Marketing, Vol. 10, No. 3, pp. 240-254.

21 Landry, T. D., Arnold, T. J. and Arndt, A. (2005) 'A compendium of sales-related literature in customer relationship management: Processes and technologies 
with managerial implications', Journal of Personal Selling and Sales Management, Vol. 25, No. 3, pp. 231-251.

22 Massey, A. P., Montoya-Weiss, M. M. and Holcom, K. (2001) 'Re-engineering the customer relationship: Leveraging knowledge assets at IBM', Decision Support Systems, Vol. 32, No. 2, pp. 155-170.

23 Collins, K. and Thompson, E. (2007) 'How to improve the customer experience', Gartner Research Report, 21 December.

24 McKim, B. and Hughes, A. M. (2001) 'How to measure customer relationship management success', The Journal of Database Marketing, Vol. 8, No. 3, pp. 224-231.

25 Hughes, T., Foss, B., Stone, M. and Cheverton, P. (2007) 'Degrees of separation: Technological interactivity and account management', International Journal of Bank Marketing, Vol. 25, No. 5, pp. 315-335.

26 Pujari, D. (2003) 'Self service with a smile? Selfservice technology (SST) encounters among Canadian business-to-business', International Journal of Service Industry Management, Vol. 15, No. 2, pp. 200-219.

27 Rackham, N. and DeVincentis, J. R. (1999) 'Rethinking the sales force', McGraw-Hill, New York.

28 Davis, F. D. (1989) 'Perceived usefulness, perceived ease of use and user acceptance', MIS Quarterly, Vol. 13, No. 3, pp. 319-340.

29 Ward, J. and Daniel, E. (2005) 'Benefits management: Delivering value from IS and IT investments', John Wiley and Son, Chichester.

30 Ward, J. and Murray, P. (1997) 'Benefits management: Best practice guidelines', Cranfield School of Management, Information Systems Research, Cranfield.

31 Shaw, R. (1998) 'Improving marketing effectiveness', The Economist Books, London.

32 Wu, I. -L. and Wu, K. -W. (2005) 'A hybrid technology acceptance approach for exploring e-CRM adoption in organizations', Behaviour and Information Technology, Vol. 24, No. 4, pp. 303-316.

33 Brown, A. D. (1994) 'Implementing MRPII: Leadership, rites and cognitive change', Logistics Information Management, Vol. 7, No. 2, pp. 6-11.

34 Pries, C. and Stone, M. (2004) 'Managing CRM implementation with consultants - CRM or change management?' Journal of Change Management, Vol. 4, No. 4, pp. 351-370.
35 Yim, F. K., Anderson, R. E. and Swaminathan, S. (2004) 'Customer relationship management: Its dimensions and effect on customer outcomes', Journal of Personal Selling and Sales Management, Vol. 24, No. 4, pp. 263-278.

36 Honeycutt, E. D., Thelen, T., Thelen, S. and Hodge, S. K. (2005) 'Impediments to sales force automation', Industrial Marketing Management, Vol. 34, No. 4, pp. 313-322.

37 Venkatesh, V. and Davis, F. D. (2000) 'A theoretical extension of the technology acceptance model: Four longitudinal field studies', Management Science, Vol. 46, No. 2, pp. 186-204.

38 Jones, E., Sundaram, S. and Chin, W. (2002) 'Factors leading to sales force automation use: A longitudinal analysis', Journal of Personal Selling and Sales Management, Vol. 22, No. 3, pp. 145-156.

39 Ahearne, M., Hughes, D. E. and Schillewaert, N. (2007) 'Why sales representatives should welcome information technology: Measuring the impact of CRM-based IT on sales effectiveness', International Journal of Research in Marketing, Vol. 24, No. 4, pp. 336-349.

40 Ekinci, Y., Gillett, P. and Stone, M. (2007) 'Deploying a CRM system in practice: Understanding the user experience', Database Marketing and Customer Strategy Management, Vol. 14, No. 3, pp. 195-224.

41 Imai, M. (1998) 'Gemba Kaizen as applied to sales management', Journal of Selling and Major Account Management, Vol. 1, No. 1, pp. 71-80.

42 Maklan, S., Know, S. and Ryals, L. (2005) 'Using real options to help build the business case for CRM investment', Long Range Planning, Vol. 38, No. 4, pp. 393-410.

43 Ittner, C. D. and Larcker, D. F. (2003) 'Coming up short on nonfinancial performance measurement', Harvard Business Review, Vol. 81, No. 11, pp. 88-95.

44 Speir, C. and Venkatesh, V. (2002) 'The hidden minefields in the adoption of sales force automation technologies', Journal of Marketing, Vol. 66, No. 3, pp. 98-111.

45 Kendrick, T. (2004) 'Strategic marketing risk management', Thomson Gee, London.

46 Bytheway, A. (1992) 'A concept model for EDI', Special working paper for the Fifth International EDI Conference, Bled, Slovenia, September. 